\title{
Detection of Epistasis for Protein and Oil Contents and Oil Quality Parameters in Peanut
}

\author{
Hari D. Upadhyaya* and Shyam N. Nigam
}

\begin{abstract}
To improve nutritional quality of peanut (Arachis hypogaea L.), it is necessary to know the importance of genetic effects. Epistasis is not considered in most genetic models. In the presence of epistasis, estimates of additive and dominance variation are biased to an unknown extent. This may affect progress of a breeding program by causing inappropriate breeding methods to be chosen. The objectives of this study were to determine the significance of epistasis in inheritance of protein and oil contents and oil quality parameters, and to estimate additive and dominance variances for the traits not influenced by epistasis. Three testers, Chico $\left(L_{1}\right), \operatorname{ICGV} 86300\left(L_{2}\right)$, and their $F_{1}$ hybrid $\left(L_{3}\right)$, were each crossed to 15 cultigens. The experiment was conducted in the 1992-1993 postrainy and 1993 rainy environments at the ICRISAT Center, Patancheru, India. Characters studied were protein, oil, eight fatty acid contents, and five derived parameters. The deviations, cultigen $\times \mathbf{L}_{1}+$ cultigen $\times \mathbf{L}_{2}-2$ cultigen $\times \mathbf{L}_{3}$, were tested to detect epistasis. Environment interacted more strongly with epistatic gene action than with additive or dominant gene action. Epistasis affected the expression of 11 traits in both environments. The additive $\times$ additive epistasis was detected for oleic acid in both environments. Additive gene action was detected for eicosenoic and polyunsaturated/saturated fatty acids $(\mathbf{P} / \mathbf{S})$ ratio in the rainy environment. Dominant gene action was detected for $P / S$ in the rainy and for eicosenoic in both environments indicating incomplete dominance for these traits.
\end{abstract}

$\mathrm{P}$ EANUT is a major oilseed crop with an annual world production of 28.0 million megagrams on 22.5 million hectares. About $70 \%$ of total peanut production is used for extraction of oil. Nutritional quality of oil is determined by its fatty acid composition. Oleic $(\mathrm{O})$, a monounsaturated fatty acid and linoleic $(\mathrm{L})$, a polyunsaturated fatty acid, account for 75 to $80 \%$ of the total fatty acids in peanut oil. The $\mathrm{O} / \mathrm{L}$ fatty acid ratio and iodine value (IV) are indicators of oil stability and self life of peanut products. To improve these and other quality traits a good knowledge of genetic systems controlling their expression is essential for choice of efficient breeding and selection procedures.

Results of previous studies using simple genetic models indicate predominance of additive gene effects for oil (Layrisse et al., 1980; Bansal et al., 1992) and fatty acid (Mercer et al., 1990) contents. Predominance of nonadditive gene effects also is reported for oil (Makne and Bhale, 1987) and fatty acid (Bansal et al., 1992) contents. Moore and Knauft (1989) reported that high oleic acid $(80 \%)$ and low linoleic acid $(2 \%)$ in a natural mutant peanut line was controlled by either one or two recessive genes, depending on the parent involved in the cross. Genetic studies for protein content reported

Groundnut Improvement Project, ICRISAT Center, Patancheru, 502 324, Andhra Pradesh, India. ICRISAT J.A. no.2226. Received 15 Dec. 1997. *Corresponding author(H.UPADHYAYA@CGNET.COM).

Published in Crop Sci. 39:115-118 (1999). predominance of additive gene effects (Layrisse et al., 1980; Makne and Bhale, 1987; Bansal et al., 1992). Because of self pollination in peanut, variation due to dominance effects and their interactions can not be effectively exploited. Additive $\times$ additive epistatic variation is useful as it can be fixed in homozygous cultivars.

The objectives of this study were to determine the importance of epistasis for protein and oil contents and oil quality parameters and to obtain estimates of additive and dominance variances for traits not influenced by epistasis in peanut.

\section{MATERIALS AND METHODS}

Procedures to develop materials and conduct of the experiments were described in detail in our earlier paper on vegetative and reproductive traits (Upadhyaya and Nigam, 1998). Three testers, Chico $\left(\mathrm{L}_{1}\right), \operatorname{ICGV} 86300\left(\mathrm{~L}_{2}\right)$, and their $\mathrm{F}_{1}$ hybrid $\left(L_{3}\right)$, were each crossed to 15 cultigens, representing Spanish, Valencia, and Virginia botanical groups. Experimental materials consisted of 17 cultigens $\left(\mathrm{L}_{1}\right.$ and $\mathrm{L}_{2}$ testers, and 15 cultigens), 31 single crosses including $\mathrm{L}_{3}$ tester, and 15 three-way crosses. The experiment was conducted in an alfisols field (Patancheru Soil Series-Udic Rhodustolf) in the 1992-1993 postrainy and 1993 rainy environments at the ICRISAT Center, Patancheru, India. In each treatment, 10 competitive plants were selected at random and harvested separately at maturity. An equal weight of sound mature seeds from each of the selected plants was bulked for use in estimating the protein, oil, and fatty acids contents.

Oil content was measured with a commercial nuclear magnetic resonance spectrometer following the procedure described by Jambunathan et al. (1985). All the readings were taken on oven dried $\left(110^{\circ} \mathrm{C}, 16 \mathrm{~h}\right)$ samples and values were expressed on a uniform $50 \mathrm{~g} \mathrm{~kg}^{-1}$ seed moisture content. Protein content was estimated with a Technicon Autoanalyser (Pulse Instrumentation Ltd., Saskatoon, SK) (Singh and Jambunathan, 1980). Fatty acid contents were estimated following the procedure described by Mercer et al. (1990). From the fatty acid estimation, five quality parameters, iodine value (IV), oleic acid (O)/linoleic acid (L) ratio, total saturated fatty acids (TSF), polyunsaturated (P)/saturated (S) ratio, and total long chain saturated fatty acids (TLCSF), were determined as described by Mozingo et al. (1988).

The method used to detect epistasis was based on triple test crosses (Kearsey and Jinks, 1968) as modified by Ketata et al. (1976). This procedure is valid regardless of gene frequencies, degree of inbreeding, and linkage relationships (Ketata et al., 1976). Statistical procedures used to detect epistasis, genotype $\times$ environment interactions in triple test cross, to estimate the additive and dominance components of variance, and degree of dominance for different traits, were previously described (Upadhyaya and Nigam, 1998). In the analysis of variance (ANOVA), the presence of epistasis is indicated if the mean squares due to $\mathrm{L}_{1 \mathrm{j}}+\mathrm{L}_{2 \mathrm{j}}-2 \mathrm{~L}_{3 \mathrm{j}}$ deviations are significantly greater than pooled error. The sum of squares (SS) due to epistasis was partitioned into SS due to $i$ (additive $x$ additive) type of epistasis and SS due to $j+1$ 
(additive $\times$ dominance + dominance $\times$ dominance) type and their significance was tested against their respective interactions with blocks. Additive (D) and dominance $\left(\mathrm{H}_{1}\right)$ components of variation were estimated from mean squares due to sums and differences within an environment, respectively. Average degree of dominance was calculated as $\left(H_{1} / D\right)^{1 / 2}$.

\section{RESULTS AND DISCUSSION}

Mean squares due total epistasis were significant for two traits (oil and oleic) in the postrainy environment and for four traits (stearic, arachidic, $\mathrm{O} / \mathrm{L}$ ratio, and TSF) in the rainy environment (Table 1). The $i$ type epistasis was detected for four traits in the postrainy and for two traits in the rainy environment. For behenic and oleic, $i$ type epistasis was detected in both the environments. The $j+1$ epistasis was detected for one trait in postrainy and for four traits in the rainy environment. For some traits for which epistasis was not detected by an $F$-test, it was detected by a $t$-test. For 11 traits (protein, oil, palmitic, stearic, behenic, lignoceric, oleic, linoleic, IV, O/L, and TSF), epistasis was detected in both environments by either an $F$-test (Table 1 ) or a $t$-test (Table 2).

Among the three botanical types of cultigens used in this study, Virginia types contributed more significant epistatic deviations for different traits than the Spanish or Valencia types. Virginia cultigens showed significance in 19 cases compared with 13 cases by Valencia and eight cases by Spanish cultigens (Table 2). However, within the three groups, contribution of different cultigens varied greatly. ICG 6163 contributed to 12 instances of significance in the Virginia group and ICG 1638 contributed in six instances in the Valencia group. In contrast, ICG 11475 in the Spanish group and ICG 6393 in the Valencia group did not contribute significantly towards epistatic deviation for any traits studied in either environment.

As reported in other crops (Burton, 1968; Malhotra and Singh, 1989), and in peanut for the vegetative and reproductive traits (Upadhyaya and Nigam, 1998), the manifestation of epistasis for quality traits was dependent on genotypes. Inclusion of several genotypes in studies designed to detect epistasis leads to better resolution (Ketata et al., 1976; Upadhyaya and Nigam, 1998). Further, both $F$ and $t$ tests should be used to detect presence of epistasis because in some cases the $F$-test may fail (Upadhyaya and Nigam, 1998). Such situations occurred for palmitic, stearic, lignoceric, linoleic, IV, $\mathrm{O} / \mathrm{L}$ ratio, and $\mathrm{P} / \mathrm{S}$ ratio in the postrainy season and for protein, oil, palmitic, lignoceric, linoleic, IV, and TLCSF in the rainy season (Tables 1 and 2). These inconsistencies in detecting epistasis may arise because the $F$-test detects whether cultigens differ in their contributions to expression of epistasis whereas the $t$-test detects whether epistatic deviations of cultigens are significantly different from zero. In the situations where the epistatic deviations are of comparable magnitude and same sign, the $F$-test may fail to detect epistasis for a given trait.

The combined analysis of variance indicated significant $i$ type epistasis $\times$ environment interactions for all

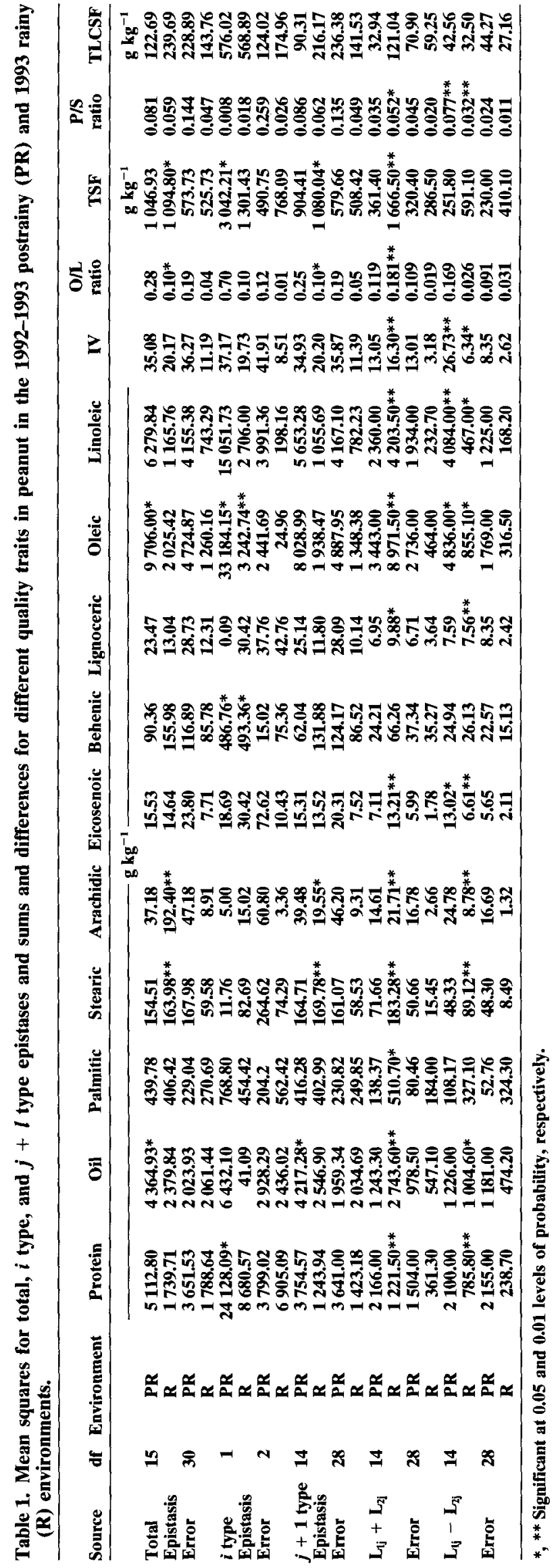




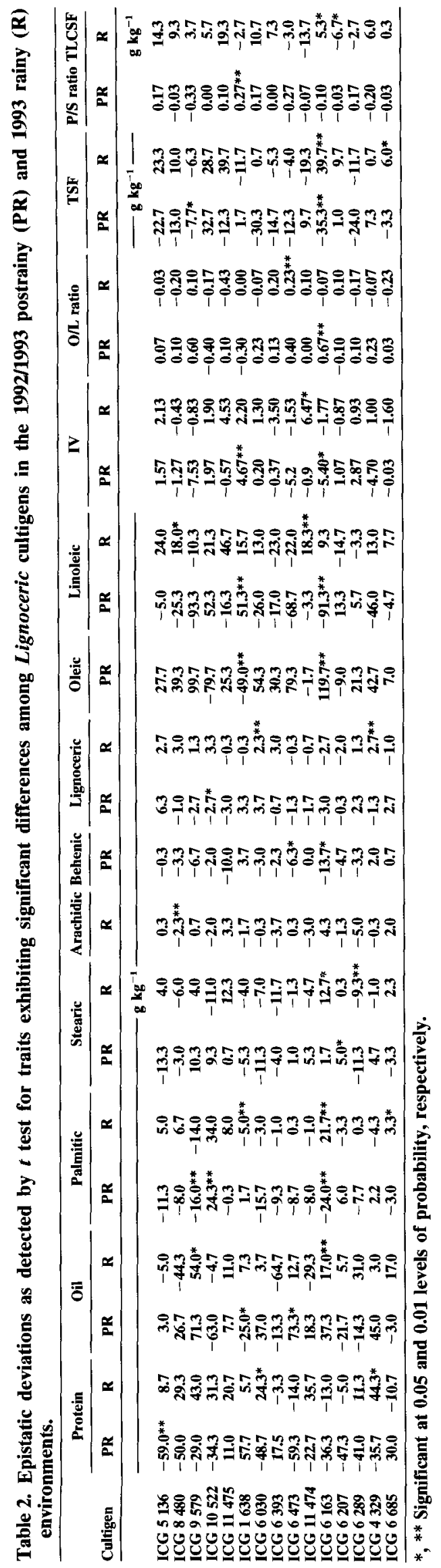

traits except stearic, arachidic, lignoceric, and $\mathrm{P} / \mathrm{S}$ ratio. The $j+1$ type epistasis $\times$ environment and total epistasis $\times$ environment interactions were significant for all traits. Similar to vegetative traits in peanut (Sandhu and Khera, 1976; Upadhyaya and Nigam, 1998), epistatic effects for quality traits were less stable due to strong interaction with environment as compared with additive (sums) and dominance (differences) effects. In other crops, epistatic effects also were found more unstable than additive and dominance effects (Perkins and Jinks, 1971; Yermanos and Allard, 1961; Gamble, 1962). Environmental interactions depend on the number of genes involved in inheritance, and as the number increases, opportunities for environmental influences become greater (Gamble, 1962). This could explain the strong epistasis by environment interaction in this study. For the 11 traits which showed significance for all three types of epistasis and environment interactions, the $i$ type epistasis interacted more strongly with environments. The $i$ type epistatic gene effects were shown more sensitive to environmental differences in previous studies (Perkins and Jinks, 1971; Upadhyaya and Nigam, 1998). The $i$ type epistasis was significant for behenic and oleic in both the environments and can be exploited in improving these traits.

Choice of testers in studies of epistasis is very important because measured epistasis refers only to the loci for which the testers differ. Discrepancies may result from the genetic differences among the testers used. The testers used in this study, Chico and ICGV 86300 , belong to different botanical groups and proved efficient in detecting epistasis for most traits (Tables 1 and 2). However, use of two or more pairs of testers or more test locations could have further improved detection of epistasis. Presence of epistasis detected in the study indicates that estimates of additive and dominance variances would have been biased for these traits if they were estimated by the procedures that assume no epistasis.

Analysis of variance for sums $\left(\mathrm{L}_{1 j}+\mathrm{L}_{2 \mathrm{j}}\right)$ showed that mean squares due to sums were nonsignificant for all the traits in the 1992-1993 postrainy environment. In the 1993 rainy environment, they were significant for all the traits except behenic and TLCSF (Table 1). The mean squares due to differences $\left(\mathrm{L}_{1 \mathrm{j}}-\mathrm{L}_{2 \mathrm{j}}\right)$ were significant for five traits (eicosenoic, oleic, linoleic, IV, and $\mathrm{P} / \mathrm{S}$ ratio) in the 1992-1993 postrainy and for 10 traits (protein, oil, stearic, arachidic, eicosenoic, lignoceric, oleic, linoleic, IV, and P/S ratio) in the 1993 rainy environment. This indicated a strong sums $X$ environment and differences $\times$ environment interactions (Table 3 ). For a given trait, additive and dominance variances were estimated for each environment only if epistasis was not detected by either an $F$-test or a $t$-test. Only dominance variance was of significance for eicosenoic in the 1992 . 1993 postrainy environment, and both additive and dominance variances were of significance for eicosenoic and $\mathrm{P} / \mathrm{S}$ ratio in the 1993 rainy environment. Dominance was incomplete for both eicosenoic, $\left.\left[H_{1} / D\right)^{1 / 2}=0.61\right]$ and P/S ratio $\left.\left[H_{1} / D\right)^{1 / 2}=0.81\right]$. Correlation between sums and differences was nonsignificant for all traits suggesting that dominant genes have both positive and negative effects for these traits. 


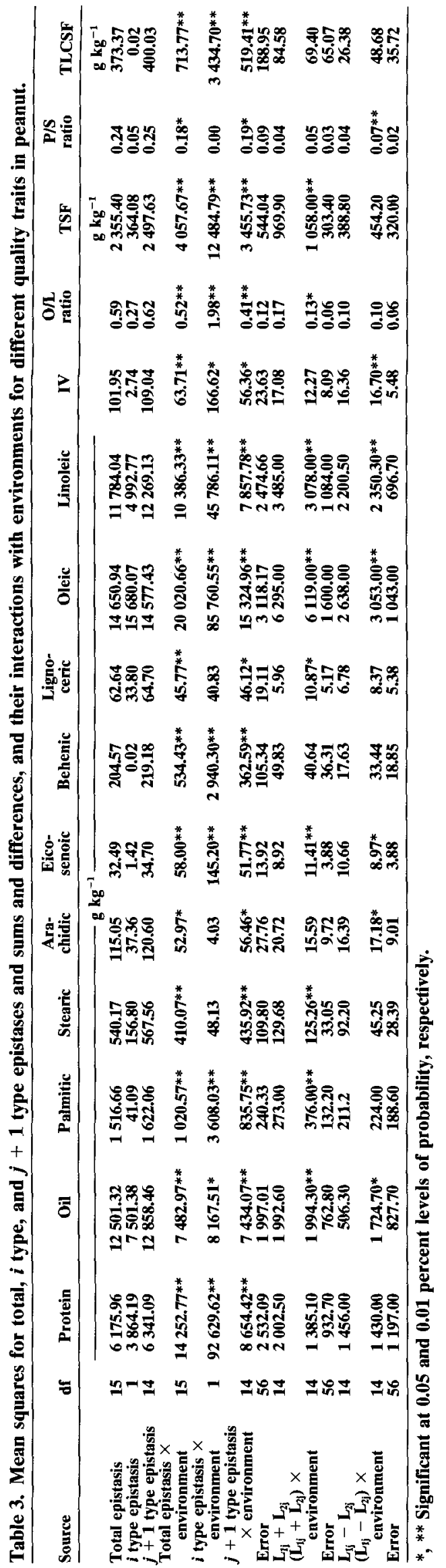

Dominance variance estimated by this procedure refers to loci which differ between the two testers. If the number of loci is less than that of all loci segregating in the population for a given trait, the dominance variance component will be underestimated. Nevertheless, significant dominance variance was observed for eicosenoic in both the environments and for $\mathrm{P} / \mathrm{S}$ ratio in the rainy environment. Estimates of additive variance for eicosenoic and P/S ratio in the 1993 rainy environment could include a component due to dominance deviations and thus could be biased upward (Mather and Jinks, 1971).

In cases (behenic and oleic acids) where $i$ type epistasis was detected across environments, selection in early generations will not be effective. In such cases, large populations should be carried forward to later generations to allow favorable gene combinations to be in a homozygous state before practicing selection.

\section{REFERENCES}

Bansal, U.K., D.R. Satija, and K.L. Ahuja. 1992. Combining ability in inter- and intra-growth habit crosses for quality traits in groundnut Arachis hypogaea L. SABRAO J. 24:1-6.

Burton, G.W. 1968. Epistasis in pearl millet forage yields. Crop Sci. 8:365-368.

Gamble, E.E. 1962. Gene effects in corn Zea mays L. III. Relative stability of the gene effects in different environments. Can. J. Plant Sci. 42:626-634.

Jambunathan, R., S.M. Raju, and S.P. Barde. 1985. Analysis of oil content of groundnuts by nuclear magnetic resonance spectrometry. J. Sci. Food Agric. 36:162-166.

Kearsey, M.J., and J.L. Jinks. 1968. A general method of detecting additive, dominance and epistatic variation for metrical traits. I Theory. Heredity 23:403-409.

Ketata, H., E.L. Smith, L.H. Edwards, and R.W. McNew. 1976. Detection of epistasis, additive and dominance variation in winter wheat (Triticum aestivum L. em Thell.). Crop Sci. 16:1-4.

Layrisse, A., J.C. Wynne, and T.G. Isleib. 1980. Combining ability for yield, protein and oil of peanut lines from South American centers of diversity. Euphytica 29:561-570.

Makne, V.G., and N.L. Bhale. 1987. Combining ability analysis for yield, protein and oil in groundnut. Ind. J. Agric. Sci. 57:617-621.

Malhotra, R.S., and K.B. Singh. 1989. Detection of epistasis in chickpea. Euphytica 40:169-172.

Mather, K., and J.L. Jinks. 1971. Biometrical genetics. 2nd ed. Chapman and Hall Ltd., London.

Mercer, L.C., J.C. Wynne, and C.T. Young. 1990. Inheritance of fatty acid content in peanut oil. Peanut Sci. 17:17-21.

Mozingo, R.W., T.A. Coffelt, and J.C. Wynne. 1988. Quality evaluations of Virginia-type peanut varieties released from 1944-1985. Southern Co-operative Series Bull. 335.

Moore, K.M., and D.A. Knauft. 1989. Inheritance of high oleic acid in peanut. J. Heredity 80:252-253.

Perkins, J.M., and J.L. Jinks. 1971. Analysis of genotype $\times$ environment interaction in triple test cross data. Heredity 26:203-209.

Sandhu, B.S., and A.S. Khera. 1976. The role of epistasis in the inheritance of yield and its components in groundnut. Crop Improv. 3:9-17.

Singh, U., and R. Jambunathan. 1980. Evaluation of rapid method for the estimation of protein in chickpea (Cicer arietinum $\mathrm{L}$ ). J. Sci. Food Agric. 31:247-254.

Upadhyaya, H.D., and S.N. Nigam. 1998. Epistasis for vegetative and reproductive traits in peanut. Crop Sci. 38:44-49.

Yermanos, D.M., and R.W. Allard. 1961. The detection of epistatic gene action in flax. Crop Sci. 1:307-310. 